\title{
THE INFLUENCE OF HOLLOW FIBERS ORIENTATION INSIDE THE POL YMERIC HOLLOW FIBER HEAT EXCHANGER ON THE HEAT TRANSFER INTENSITY
}

\author{
E. Bartuli ${ }^{*}$ T. Brožová** ${ }^{* *}$ M. Raudenský ${ }^{* * *}$
}

\begin{abstract}
One type of polymeric heat exchanger is polymeric hollow fiber heat exchanger (PHFHE). PHFHEs use polymeric microchannels as the heat transfer surface. The main purpose of this work was to determine an optimal arrangement of polymeric hollow fibers inside a PHFHE shell-and-tube type. The object of study were two PHFHEs which consist of a polymeric hollow fibers with an outer diameter of $0.8 \mathrm{~mm}$ and inner diameter $0.65 \mathrm{~mm}$. PHFHE-1 fibers were parallel to the liquid flow and in PHFHE-2 fibers were twisted by an angle of $22.5^{\circ}$. The heated working fluid flowed in the shell of PHFHEs and cooling water was inside the hollow fiber. Heat transfer coefficients on the outer surface of hollow fibers were obtained experimentally. It was shown that PHFHE-2 has 12.5\% higher overall heat transfer coefficient comparing with PHFHE-1.
\end{abstract}

Keywords: hollow fiber, heat exchanger, heat transfer, heat transfer coefficient

\section{Introduction}

In different fields, such as heat recovery system, evaporative cooling system, desiccant cooling system, electronic device cooling and water desalination system (Chen, 2016) the polymeric heat exchangers is becoming more and more popular. Krasny (2016) made a comparative study of a polymeric heat exchanger and a metal finned tube heat exchanger intended for an use as an automobile radiator and showed that the thermal performances of polymeric heat exchanger were commensurable to the metal one.

Such a property of polymeric heat exchangers as the corrosive resistant makes the possibility to use them in chemical industry. (Jia et al., 2001) presented an experimental study on the heat transfer performance of wet flue gas heat recovery system using a plastic longitudinal spiral plate heat exchanger.

Another important advantage of polymer heat exchangers is that their production uses less energy than the production of metal heat exchangers (Zarkadas, 2004). Low weight, smooth surface, simplicity of shaping and producing, resistance to fouling it are another significant advantages of plastic heat exchangers (Astrouski, 2015).

Polymeric hollow fiber heat exchanger (PHFHE) (Fig. 1) is one of the different types of polymer heat exchanger (Astrouski, 2012). Using thin-wall polymeric hollow fibers as heat exchanger tubes was first proposed by Zarkadas (2005) as a new type of heat exchanger for lower temperature/pressure applications. This heat exchanger utilizes polymeric microchannels as the heat transfer surface. The outer diameter of these microchannels is smaller than $1 \mathrm{~mm}$. The heat exchanger is made of hundreds of such fibers, which result in a very large heat transfer area compared to the size of the entire heat exchanger.

Ing. Erik Bartuli: Heat Transfer and Fluid Flow Laboratory, Brno University of Technology; Technická 2896/2; 616 69, Brno; CZ, erik.bartuli1@vut.cz

** Ing. Tereza Brožová: Heat Transfer and Fluid Flow Laboratory, Brno University of Technology, Technická 2896/2; 616 69, Brno; CZ, tereza.brozova@vut.cz

*** prof. Ing. Miroslav Raudenský, CSc.: Heat Transfer and Fluid Flow Laboratory, Brno University of Technology; Technická 2896/2; 616 69, Brno; CZ, miroslav.raudensky@vut.cz 


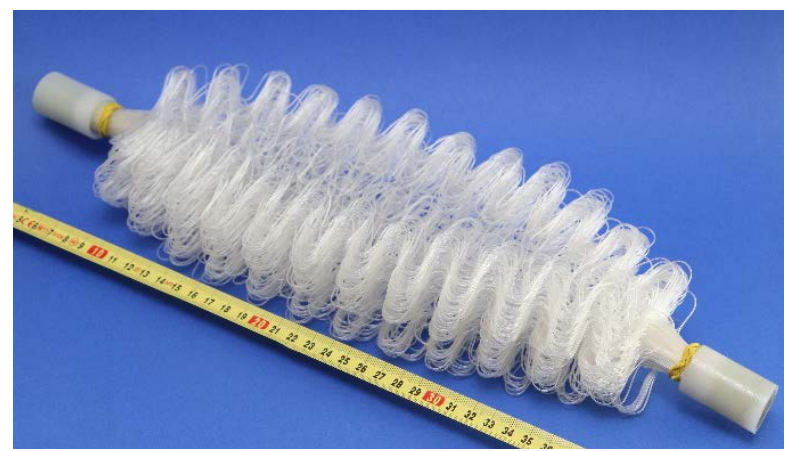

Fig. 1: Polymeric hollow fiber heat exchanger

\section{Experimental section}

The aim of this work was to investigate the influence of heat transfer on the outer surface of the hollow fibers on the overall heat transfer coefficients of the PHFHE.

Equation (2) was used to describe the heat transfer coefficient dependence on the thermal resistance:

$$
a=\frac{1}{R}
$$

where $\alpha$ is the heat transfer coefficient.

Total thermal resistance of heat exchanger can be presented as a sum of the resistances:

$$
\mathrm{R}_{\text {total }}=\mathrm{R}_{\text {in }}+\mathrm{R}_{\text {wall }}+\mathrm{R}_{\text {out }}
$$

where $\mathrm{R}_{\mathrm{in}}$ is the thermal resistance of the heat transfer from the hot fiber wall to the fluid inside the fiber, $R_{\text {wall }}$ is the thermal resistance of the fiber wall, $R_{\text {out }}$ is the thermal resistance of the heat transfer from the hot medium outside the fiber to the fiber wall.

Each fiber can be considered as a capillary tube and the heat exchange inside the tubes with a diameter smaller than $1 \mathrm{~mm}$ is very intensive (Fig. 2), and does not depend on flow rate inside a fibers. So $\mathrm{R}_{\text {in }}$ can be considered as a constant for the given type of PHFHE. $\mathrm{R}_{\text {wall }}$ depends on the wall thickness. For this PHFHE hollow fibers with a wall thickness of $0.075 \mathrm{~mm}$ were used. Such a value was determined by strength properties of fibers. Further reduction in wall thickness would adversely affect the reliability of the heat exchanger. So, for this type PHFHE the value $\mathrm{R}_{\text {wall }}$ can also be considered as a constant. That is why the main attention in this paper will be focused on the intensity of the heat transfer on the outer surface of the fibers $\mathrm{R}_{\text {out. }}$.

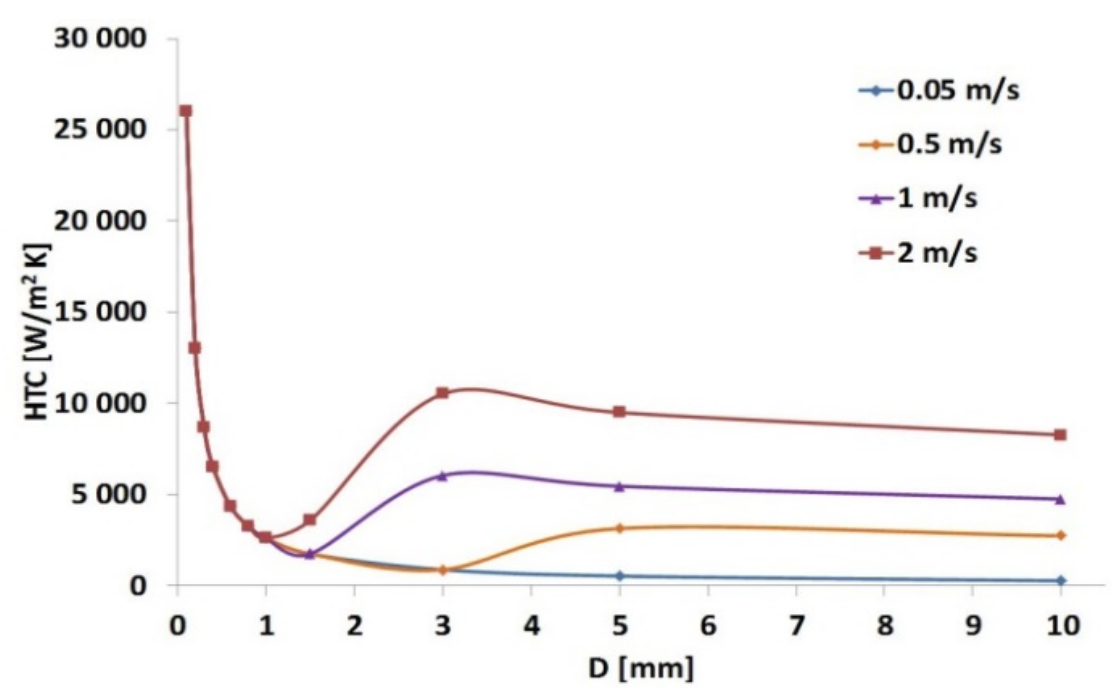

Fig. 2: Dependence of heat transfer coefficients on the tube diameter 
Two heat exchangers shown in Fig. 3 were tested in the frame of this work. Heat exchangers were constructed as shell-and-tube with a water as a working fluid. Hollow fibers were made of polycarbonate. Potting area diameter of the shell was equal to $40 \mathrm{~mm}$. The water temperature inside the fibers was equal to $27{ }^{\circ} \mathrm{C}$, and the temperature of water flown around the hollow fibers was set as $80{ }^{\circ} \mathrm{C}$. The liquid flow rate inside the fibers was $660 \mathrm{l} / \mathrm{h}$, and the fluid flow rate in the shell varied from 200 to $1000 \mathrm{l} / \mathrm{h}$.

In order to increase the PHFHE efficiency, the method of increasing heat transfer coefficients on the outer surface of hollow fibers by changing the hollow fibers orientation inside the heat exchanger was considered. One variant of such optimization was described by Yan (2014), author used a mesh inside the heat exchanger for hollow adjustment. In our work two variants of hollow fibers position were studied: in PHFHE-1 fibers were parallel to the liquid flow and in PHFHE-2 fibers were twisted by an angle of $22.5^{\circ}$. Fibers amount of potting area for PHFHE- 1 was $30 \%$ and the heat transfer area was $0.52 \mathrm{~m}^{2}$, for PHFHE-2 these values were equal to $33 \%$ and $0.54 \mathrm{~m}^{2}$ correspondently.

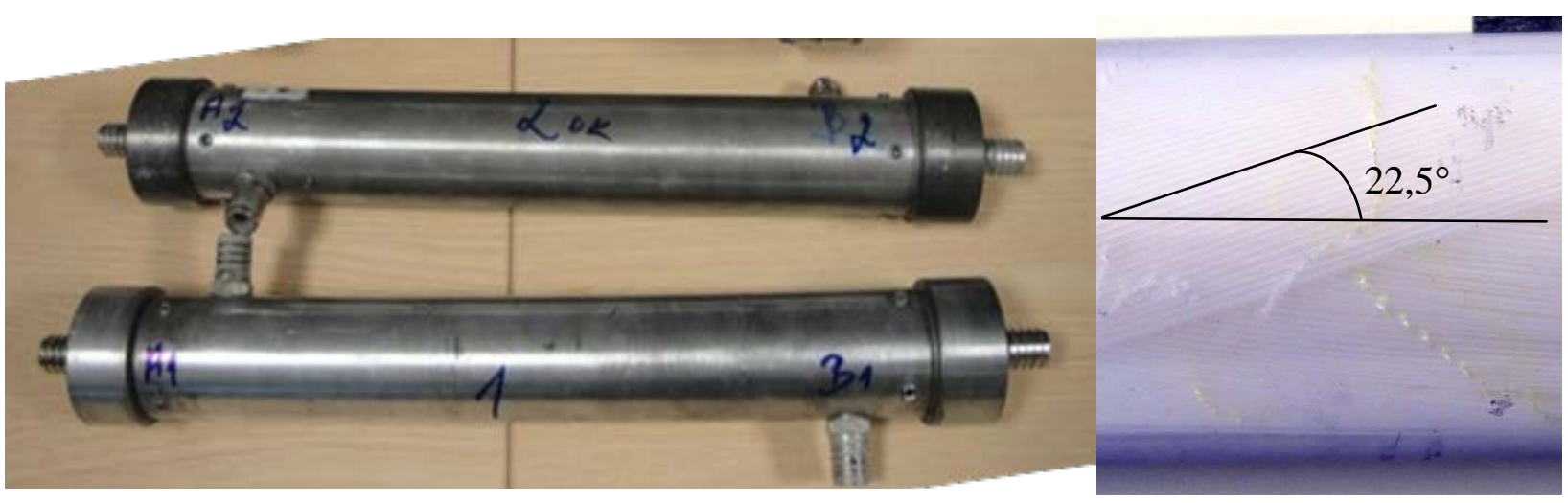

Fig. 3: PHFHE-1 and PHFHE-2 in stainless steel shell (left) and the insert of the PHFHE with twisted fibers (right)

\section{Results and Discussion}

The dependence of the PHFHE overall heat transfer coefficients on the liquid flow rate in the shell is presented in the Fig. 4. It can be seen that at low flow rates the heat transfer coefficients are almost the same. However, the heat transfer coefficients for the PHFHE-2 with twisted hollow fibers are more than $10 \%$ higher compared with the PHFHE-1 with non-twisted fibers with the increasing liquid flow rate over $800 \mathrm{l} / \mathrm{h}$. At the liquid flow rate of $1000 \mathrm{l} / \mathrm{h}$ overall HTC for PHFHE-2 achieve the maximum value of $1091 \mathrm{~W} / \mathrm{m}^{2} \mathrm{~K}$, wherein the maximal heat transfer coefficient of the PHFHE-1 was $970 \mathrm{~W} / \mathrm{m}^{2} \mathrm{~K}$.

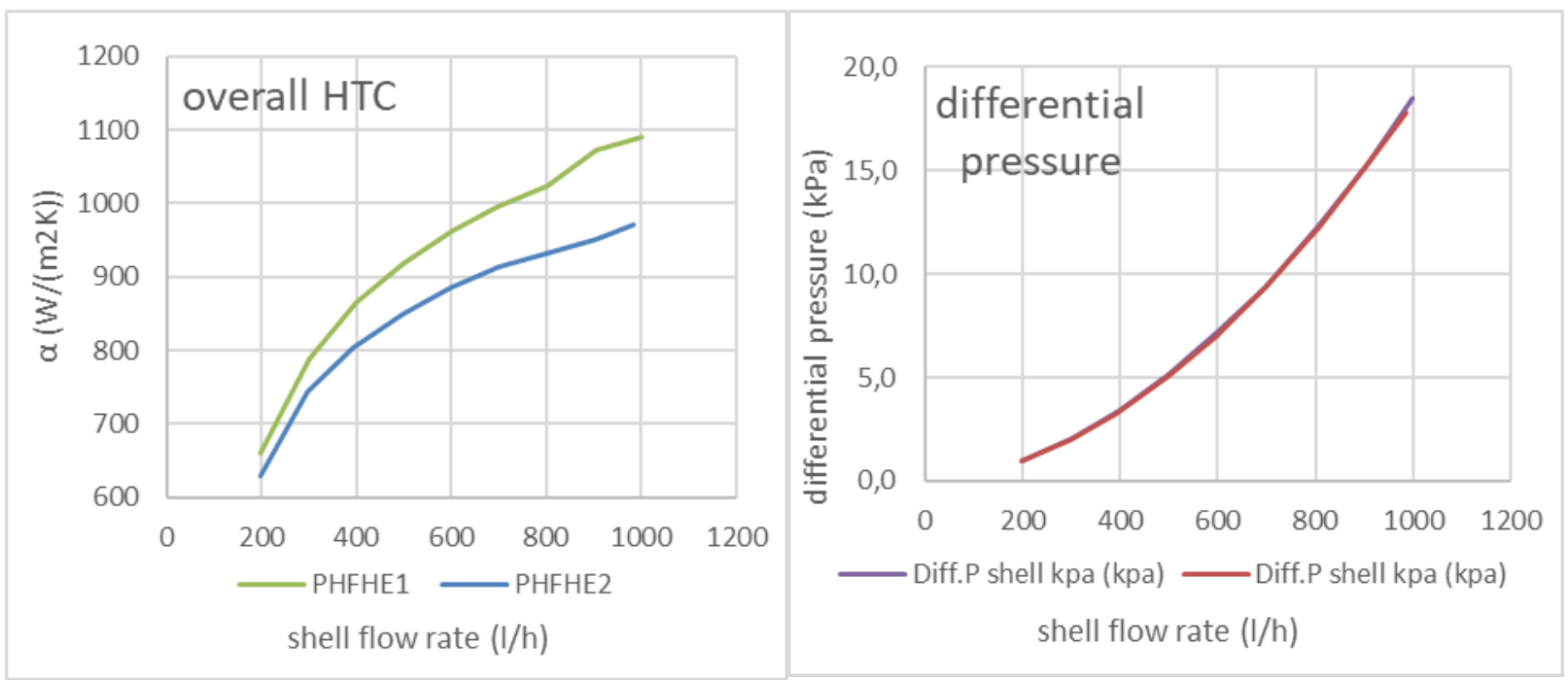

Fig. 4: Overall heat transfer coefficient of the PHFHE1 and PHFHE2 (left). Differential pressure of the PHFHE1 and PHFHE2 (right). 
Such an increase in overall HTC for the PHFHE-2 with twisted hollow fibers can be explained by the fact that the declination of the hollow fiber axis with respect to the liquid flow in the shell leads to the liquid flow turbulization and as a consequence to the heat transfer coefficients on the hollow fibers outer surface increase.

Moreover, the pressure losses for both of heat exchangers were absolutely identic as can be seen from the Fig. 4.

\section{Conclusions}

In this paper, the effect of the hollow fibers arrangement inside the polymeric heat exchanger on the overall heat transfer coefficient was studied. Two samples with different hollow fibers orientations were tested: in PHFHE-1 fibers were parallel to the liquid flow and in PHFHE-2 fibers were twisted by an angle of $22.5^{\circ}$.

The overall HTC of PHFHE-2 with twisted hollow fibers achieved a maximum value of $1091 \mathrm{~W} / \mathrm{m}^{2} \mathrm{~K}$ and for PHFHE-1 with fibers parallel to the liquid flow a maximum overall HTC was equal to $970 \mathrm{~W} / \mathrm{m}^{2} \mathrm{~K}$. Twisting of the fibers led to the increase of the overall heat transfer coefficient by $12.5 \%$, while the pressure losses in the heat exchanger remained the same. It should be noted that the active heat exchanger's areas were almost the same for both of the heat exchangers. So, the method of twisting hollow fibers inside the PHFHE results on the heat exchanger efficiency increase and can be applied for producing the shell-and-tube PHFHEs.

\section{Acknowledgement}

The research leading to these results has received funding from the MEYS under the National Sustainability Programme I (Project LO1202) and from the project EPSILON No.TH01020139, Heat exchangers with polymeric hollow fibres for energetic systems of buildings, granted by the Technology Agency of the Czech Republic.

\section{References}

Astrouski I., Ruadensky M., Dohnal M. (2015) Fouling of polymeric hollow fiber heat exchanger by wastewater, Chemical Engineering Transactions, 45, pp. 949-954.

Astrouski I., Ruadensky M. (2012) The study of polymeric hollow fiber heat exchangers, Engineering Mechanics 2012, ITAM AS CR, Prague, pp. 47-57.

Chen X., Su Y., Reay D., Riffat S. (2016) Recent research developments in polymer heat exchangers, Renewable and Sustainable Energy Reviews, 60, pp. 1367-1386.

Jia L., Peng X., Sun J., Chen T. (2001) An experimental study on vapor condensation of wet flue gas in a plastic heat exchanger, Heat Transfer-Asian Research, 30, pp. 571-580.

Krasy I., Astrouski I., Raudensky M. (2016) Polymeric hollow fiber heat exchanger as an automotive radiator, Applied Thermal Engineering, 108 , pp. 798-803.

Yan X., Li B., Liu B., Zhao J., Wang Y. Li H. (2014) Analysis of improved novel hollow fiber heat exchanger, Applied Thermal Engineering, 67 , pp. 114-121.

Zarkadas D., Li B., Sirkar K. (2005) Polymeric hollow fiber heat exchangers (PHFHEs): a new type of compact heat exchanger for lower temperature applications, Proceedings of the ASME summer heat transfer conference, pp.429-38.

Zarkadas, D. and Sirkar, K. (2004) Polymeric hollow fiber heat exchangers: an alternative for lower temperature applications. Industrial \& Engineering Chemistry Research, 43(25), pp. 8093-8106. 